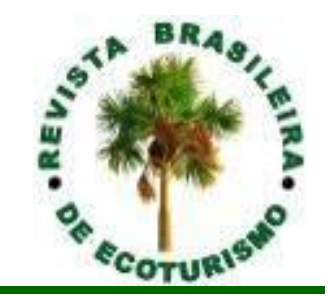

\title{
Percepção dos stakeholders sobre os impactos do fechamento das cavernas turísticas do PETAR em 2008
}

\section{Stakeholders' perception about the impacts of the closure in 2008 of tourist caves of PETAR (SP, Brazil)}

\author{
Francesca Antoniella Borsanelli, Zysman Neiman, Heros Augusto Santos Lobo
}

\begin{abstract}
RESUMO: O Parque Estadual Turístico do Alto Ribeira (PETAR) é um reconhecido destino de turismo de cavernas. Em 2008, a visitação no Parque foi embargada, afetando a visitação turística e as comunidades locais. O objetivo da presente pesquisa é analisar a visão dos stakeholders sobre os impactos causados ao turismo e à comunidade local pelo fechamento temporário das cavernas turísticas. Para tanto, 50 stakeholders de diferentes grupos representativos do turismo local foram entrevistados. Nos resultados, dentre os impactos citados como positivos, destacam-se o reordenamento da visitação, o acréscimo na segurança para trabalhadores e visitantes e a maior efetividade na conservação. Quanto aos impactos negativos, ressaltam-se os prejuízos financeiros para os envolvidos com o turismo e problemas decorrentes dos novos padrões de visitação. Notou-se também uma mudança no perfil de visitantes do Parque. Entre as conclusões obtidas, destaca-se o aspecto traumático e de caráter impositivo das mudanças realizadas, gerando diversos transtornos evitáveis para a população local envolvida direta e indiretamente com o turismo.
\end{abstract}

PALAVRAS-CHAVE: Ecoturismo; Espeleoturismo; Gestão do Turismo; Destinos Turísticos; Comunidades Receptoras.

ABSTRACT: The State Tourist Park of Alto Ribeira (PETAR) is a recognized cave tourism destination. In 2008, visitation at the Park was embargoed, affecting tourist visitation and local communities. The objective of this research is to analyze the point of view of stakeholders about the impacts caused to tourism and the local community by the temporary closure of tourist caves. Therefore, 50 stakeholders from different stakeholders related with the tourism were interviewed. In the results, among the impacts mentioned as positive, the reorganization of visitation, the increase in safety for workers and visitors and the improvement in conservation are highlighted. On the other hand, the negative impacts are financial losses for those involved with tourism and problems concerning the new visitation patterns. There was also a change in the profile of visitors to the Park. Among the conclusions, the traumatic and imposing aspect of the changes made stands out, generating several preventable disorders for the local population directly and indirectly involved with tourism.

KEYWORDS: Ecotourism; Cave Tourism; Tourism Management; Tourism Destination; Host Community. 


\section{Introdução}

O Vale do Ribeira, localizado no Estado de São Paulo, possui um dos mais importantes contínuos de Floresta Atlântica protegida por Unidades de Conservação (UCs) do Brasil (ALVES, 2004). Destas UCs, destaca-se o Parque Estadual Turístico do Alto Ribeira (PETAR). Criado em 1958, o PETAR protege uma parcela significativa do patrimônio espeleológico brasileiro, por meio das cavernas localizadas em seu interior (Unesco, 1999; KARMANN; FERRARI, 2002). No seu entorno existem comunidades locais, com destaque sob a ótica do turismo para o bairro da Serra, um distrito de Iporanga distante $13 \mathrm{~km}$ da sede municipal e a 26 km do município de Apiaí (MARINHO, 2002).

O Bairro da Serra tem sua economia baseada no fluxo turístico do Parque (HOGAN et al., 1999; FOGAÇA, 2008), que se construiu historicamente em função das restrições de uso e ocupação da terra advindas da criação do Parque. Ao longo das décadas de 1970 a 1990, o turismo se desenvolveu com poucas políticas públicas e de forma espontânea. Em feriados prolongados, o fluxo turístico extrapolava a capacidade operacional do Parque e a capacidade de carga turística das cavernas. A falta de clareza nas regras de visitação e de um padrão mínimo de segurança resultou em acidentes, mortes e impactos ambientais nas cavernas (SCALEANTE, 2003; LOBO, 2017).

Este cenário, aliado à falta de um Plano de Manejo do Parque e dos Planos de Manejo Espeleológico (PMEs) das cavernas turísticas, culminou na interdição da visitação nas cavernas em 20 de fevereiro de 2008. O embargo ocorreu devido à uma ação civil pública que foi conduzida pelo Ministério Público Federal, na qual foi réu a Fundação Florestal do Estado de São Paulo - o órgão responsável pela gestão do Parque -, em conjunto com o Instituto Brasileiro do Meio Ambiente e dos Recursos Naturais Renováveis e o Centro Nacional de Pesquisa e Conservação de Cavernas do Instituto Chico Mendes de Conservação da Biodiversidade - estes, em função da responsabilidade constitucional sobre as cavernas brasileiras. Segundo Rabinovici e Neiman (2008, s.p.), "os argumentos pautavam-se na situação preocupante em que se encontrava [...] o PETAR e suas cavernas. Grande parte dos problemas devia-se à ausência de Plano de Manejo e ao reduzido número de funcionários". O embargo resultou na assinatura de um Termo de Ajustamento de Conduta (TAC), permitindo a retomada da visitação em 19 de abril de 2008, com regras definidas, diversas restrições à visitação e firmando o compromisso de elaboração dos PMEs destas cavernas (BORSANELLI; LOBO, 2013).

Considerando este panorama, foi realizada uma pesquisa que buscou identificar os impactos causados à comunidade local em consequência ao fechamento das cavernas em 2008 e que perduram até os dias atuais. Os principais fatos que justificaram a realização desta pesquisa foram: a) o TAC ainda vigora após mais de uma década, mesmo com os PMEs já aprovados; b) a grande dependência econômica local com o turismo; e c) as variações de fluxo e satisfação de visitantes pós-2008 (BORSANELLI; LOBO, 2013).

Estudos anteriores que apresentaram contribuições teóricas fundamentais para a pesquisa realizada versaram sobre a mudança periódica do perfil de visitantes, dos iniciantes-exploradores para o turismo formal dos pacotes de viagens, ocasionando alterações nas formas de planejar e executar a atividade turística (BUTLER, 2006) e, por consequência, nas comunidades receptoras (PAVOVLICH, 2003). Estas podem estar entre as mais afetadas do processo, 
pois nem sempre conseguem adaptar-se às mudanças na mesma velocidade em que os processos de mercado ocorrem (BARTHOLO Jr et al., 2011). Assim, visando identificar estas possíveis alterações consequentes e outros aspectos, a pesquisa realizada considerou a visão dos principais protagonistas do turismo no PETAR, denominados stakeholders. No contexto do turismo, este termo é utilizado para designar pessoas diretamente envolvidas e afetadas pelo turismo e que possuem algum poder de decisão sobre a atividade (SAUTTER; LEISEN, 1999; BYRD, 2007; IMRAN et al., 2014). Os stakeholders têm influência no desenvolvimento do turismo local, vivendo direta ou indiretamente da atividade (SAVAGE et al., 1991; BYRD, 2007). No contexto do turismo em áreas protegidas, quatro grupos particularmente influentes citados por Rosa et al. (2016) são considerados: comunidades locais, gestão e demais funcionários da UC, operadores turísticos, e visitantes.

\section{Aspectos metodológicos e procedimentos de pesquisa}

\section{Caracterização da área de estudo}

O PETAR localiza-se no Vale do Ribeira, no sudoeste paulista (Figura 1), a $330 \mathrm{~km}$ da cidade de São Paulo e a $196 \mathrm{~km}$ da cidade de Curitiba. O Parque conta com $35.884,28$ ha, sendo que sua área se distribui entre os municípios de Iporanga (SP) e Apiaí (SP), além de possuir ao seu redor o distrito do Bairro da Serra (em Iporanga); e outras comunidades tradicionais (MARINHO, 2002).

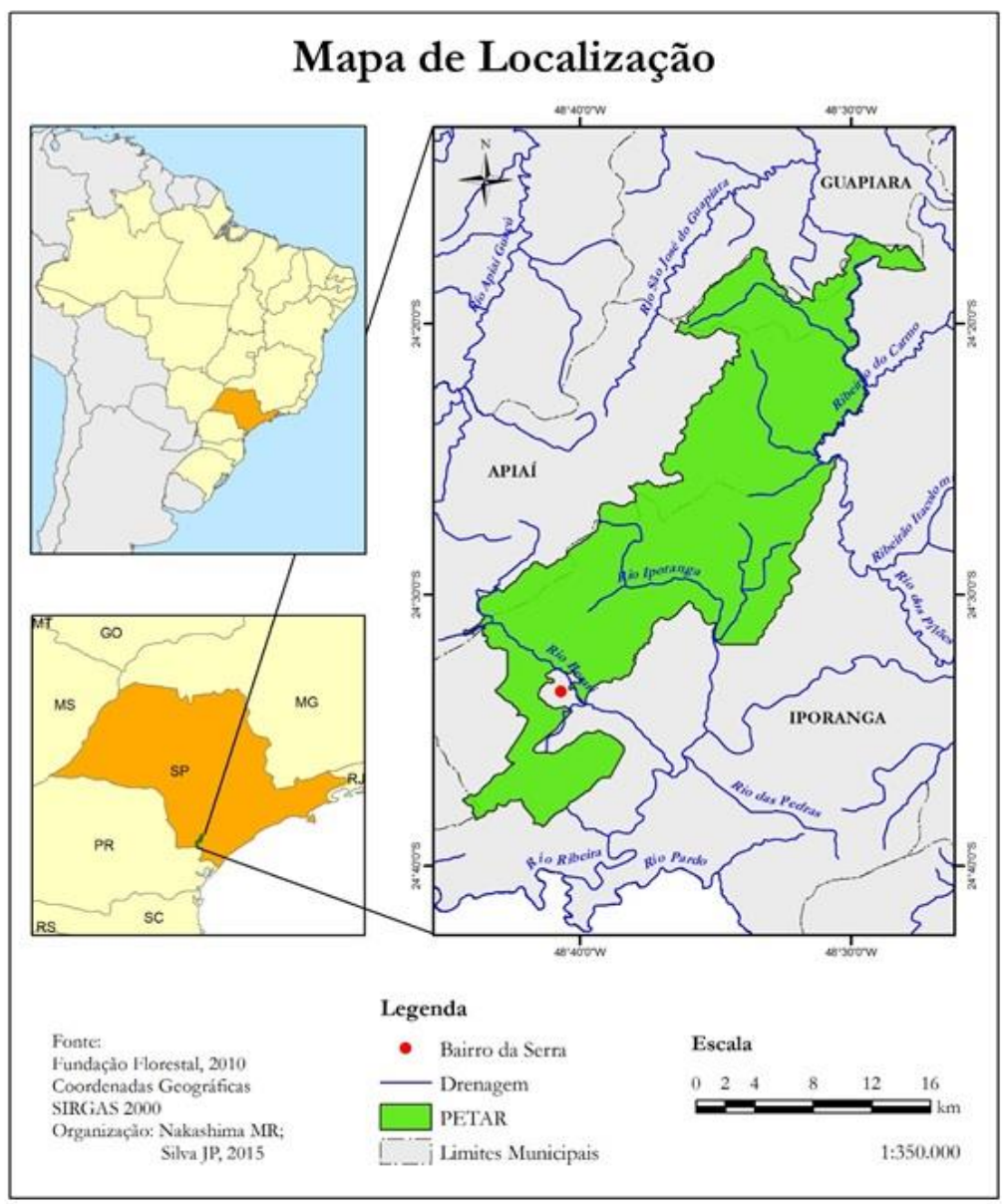

Figura 1: Localização do PETAR.

Figure 1: Location of PETAR.

Fonte: Fundação Florestal, 2010.

Source: Fundação Florestal, 2010. 
O relevo do PETAR é montanhoso, sendo uma das mais relevantes áreas cársticas e espeleológicas do Brasil (KARMANN; FERRARI, 2002; INSTITUTO EKOS, 2010). O Parque conta, também, com rios, cachoeiras e outros atrativos turísticos, mas são as cavernas (Figura 2) o seu principal chamariz turístico. Atualmente são 12 cavernas abertas à visitação, distribuídas em 4 núcleos de visitação - Santana, Ouro Grosso, Caboclos e Casa de Pedra (INSTITUTO EKOS, 2010).

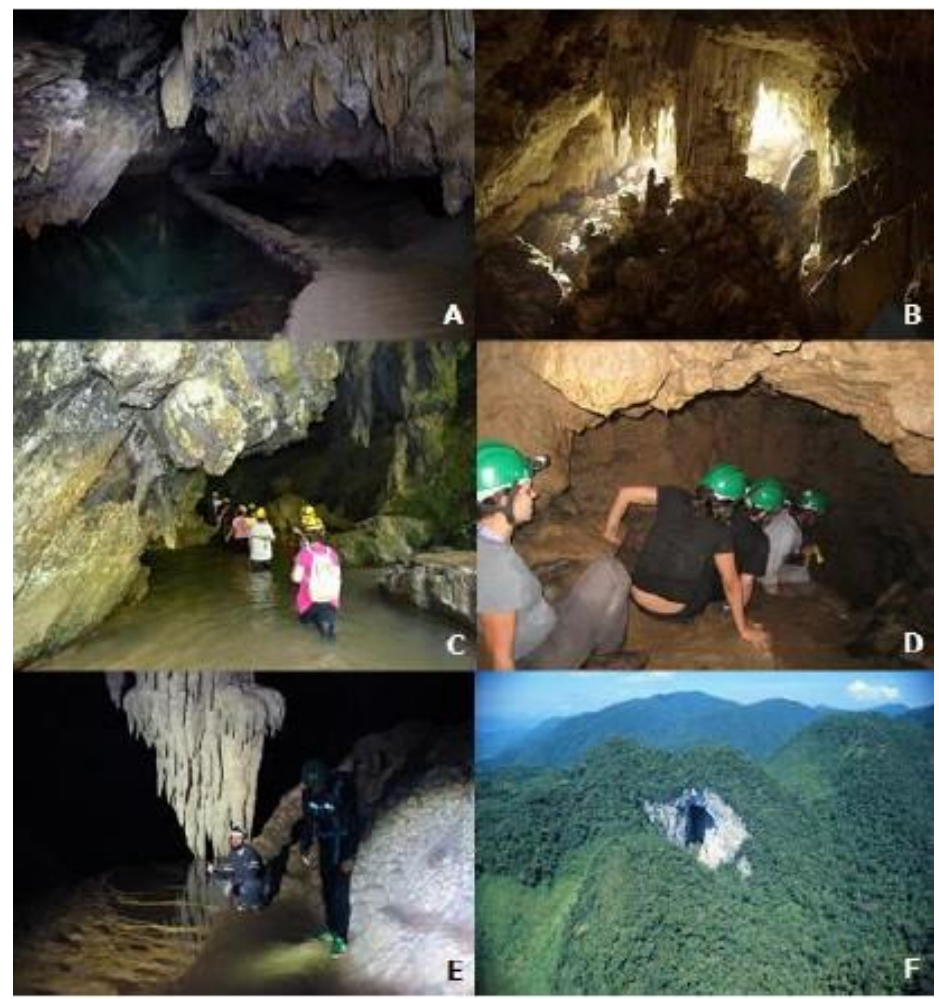

Figura 2: Cavernas turísticas do PETAR.

Figure 2: Touristic caves of PETAR.

Fonte: Francesca Antoniella Borsanelli (2010).

Source: Francesca Antoniella Borsanelli, (2010).

\section{Metodologia}

A pesquisa de campo tomou por base a realização de entrevistas com os principais stakeholders do PETAR, selecionados considerando sua participação histórica e ligação com o turismo. Para compreender o discurso e as considerações específicas dos stakeholders, estes foram agrupados em 6 categorias: Agências Pedagógicas (A.P.); Equipe e Órgão Gestor do PETAR (E.O.P.); Outros Órgãos e Instituições (O.O.I.); Trade Turístico de Apiaí (T.T.A.); Trade Turístico do Bairro da Serra (T.T.S.); e Trade Turístico de Iporanga (T.T.I.).

A categoria Agências Pedagógicas (A.P.) refere-se às empresas que trabalham com o turismo pedagógico no PETAR, levando grupos estudantis de escolas e universidades para conhecerem o parque. Os stakeholders desta categoria são proprietários de empresas deste setor. Todas estas empresas são sediadas em outras localidades.

Os stakeholders da categoria denominada Equipe e Órgão Gestor do PETAR (E.O.P.) são funcionários do Parque, além de outros funcionários do 
órgão que o administra. Já os stakeholders da categoria Outros Órgãos e Instituições (O.O.I.) são ligados a outros órgãos, tanto locais como de outras regiões, os quais são ligados direta ou indiretamente ao PETAR, exercendo influência sobre aspectos sociais, econômicos e turísticos na região.

Ambas as seguintes categorias Trades Turísticos do Bairro da Serra (T.T.S.), Iporanga (T.T.I.) e Apiaí (T.T.A.) referem-se à entrevistas com stakeholders que são empresários da hotelaria, agenciamento receptivo, alimentos \& bebidas, assim como monitores ambientais locais e também de outras regiões.

Foram realizadas entrevistas com questões abertas (Quadro 1), as quais foram previamente testadas em campo e ajustadas.

Quadro 1: Perguntas das entrevistas.

Frame 1: Interview questions.

- $\quad$ Desde quando você está envolvido com o turismo na região?
- O que o embargo das cavernas trouxe de positivo e negativo para o uso público?
O que o embargo das cavernas trouxe de positivo e negativo para as comunidades?
O perfil do visitante que vem ao PETAR hoje é o mesmo de antes do fechamento? Se
não, o que mudou?
- Você percebeu alguma modificação no fluxo de visitantes, desde o embargo?

As entrevistas foram realizadas e gravadas com autorização dos stakeholders entre fevereiro e março de 2017. A amostra total foi de 50 stakeholders entrevistados, entre as diferentes categorias. Os entrevistados foram codificados considerando as siglas de cada grupo e números (ex.: Trade Turístico de Iporanga: TTI 1, TTI 2). A análise do conteúdo das entrevistas considerou as seguintes etapas: preparação das informações por meio da transcrição literal das entrevistas; transformação do conteúdo transcrito em unidades similares entre si, por meio de palavras-chave; e a classificação das unidades em categorias, definidas por construtos textuais; e a seleção de partes relevantes das entrevistas, as quais corroboram a discussão dos resultados, e por isso seguem dispostas na sessão intitulada resultados e discussão (OLABUENA; ISPIZUA 1989; MORAES, 1999).

\section{Resultados e discussão}

\section{Possíveis modificações no fluxo turístico e no perfil dos visitantes}

A redução no fluxo turístico no PETAR (Figura 3), em função do embargo de 2008 já havia sido registrada por pesquisas anteriores (LOBO, 2008) e foi pontuada por todos os grupos de stakeholders. Este aspecto foi considerado negativo, dada a dependência da região - em especial do Bairro da Serra - em relação ao turismo. Por outro lado, os entrevistados também pontuaram sobre a retomada no aumento do número de visitantes, ocorrida pouco tempo depois do embargo. 


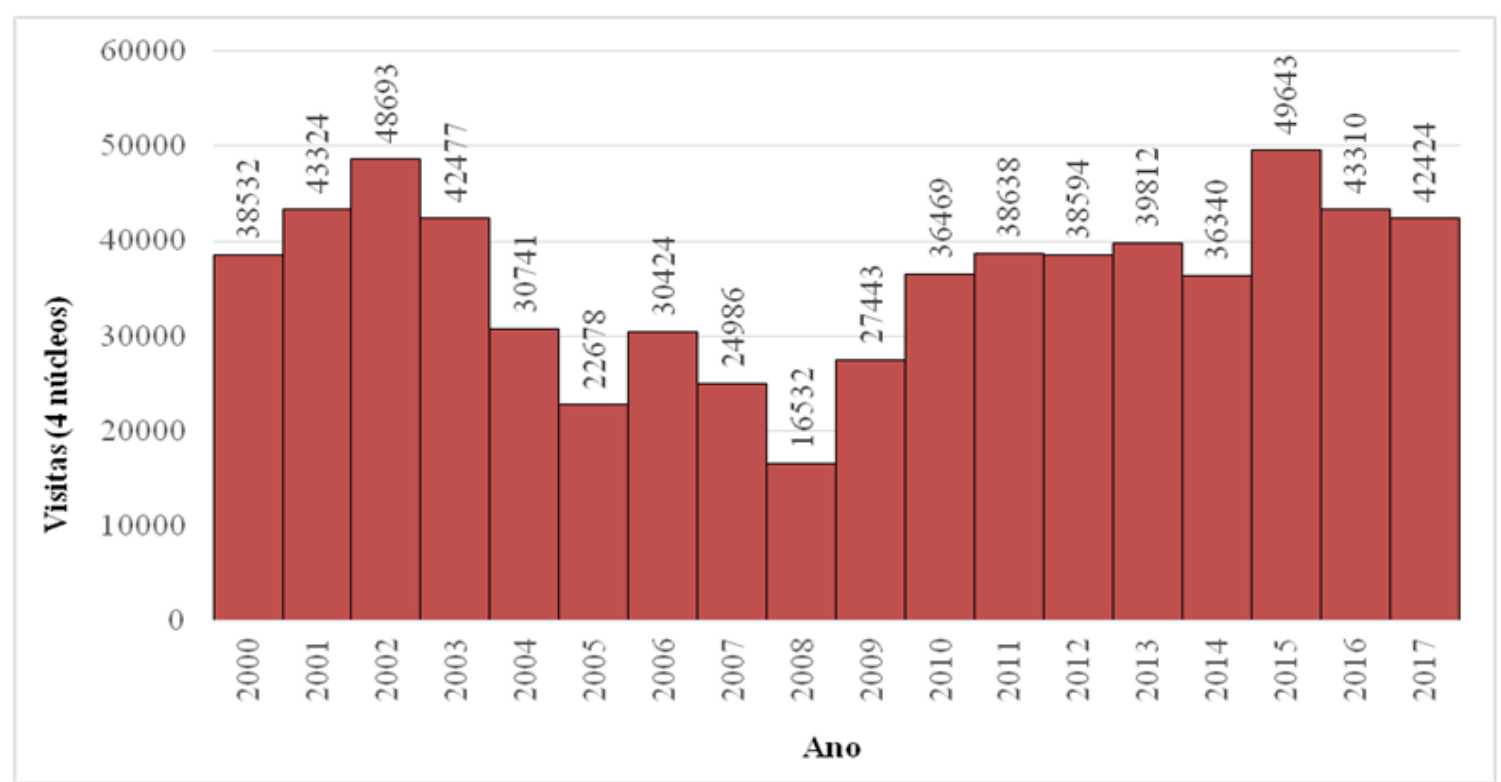

Figura 3: Total anual de visitas no PETAR (2000-2017).

Figure 3: Annual visits to PETAR (2000-2017).

Fonte: Gestão do PETAR (2018).

Source: PETAR management team (2018).

Os dados de visitação da Figura 3 evidenciam que os problemas de visitação apareceram desde 2003 - com a redução em relação a 2002. Porém, observa-se que o ano de 2008 foi o mais baixo de toda a série histórica considerada. Este fato é ainda mais drástico, considerando que o fluxo de visitantes no Parque chegou a zerar por algumas semanas após o embargo (LOBO, 2008), mesmo com os demais roteiros permanecendo abertos. A visitação voltou a aumentar desde 2009, evidenciando que, em relação à quantidade de visitas anuais, o impacto do fechamento das cavernas foi temporalmente pontual. Em contrapartida, estes visitantes pós-2008 possuíam outro perfil em relação àqueles que visitavam o Parque antes de 2008 (Figura 4).

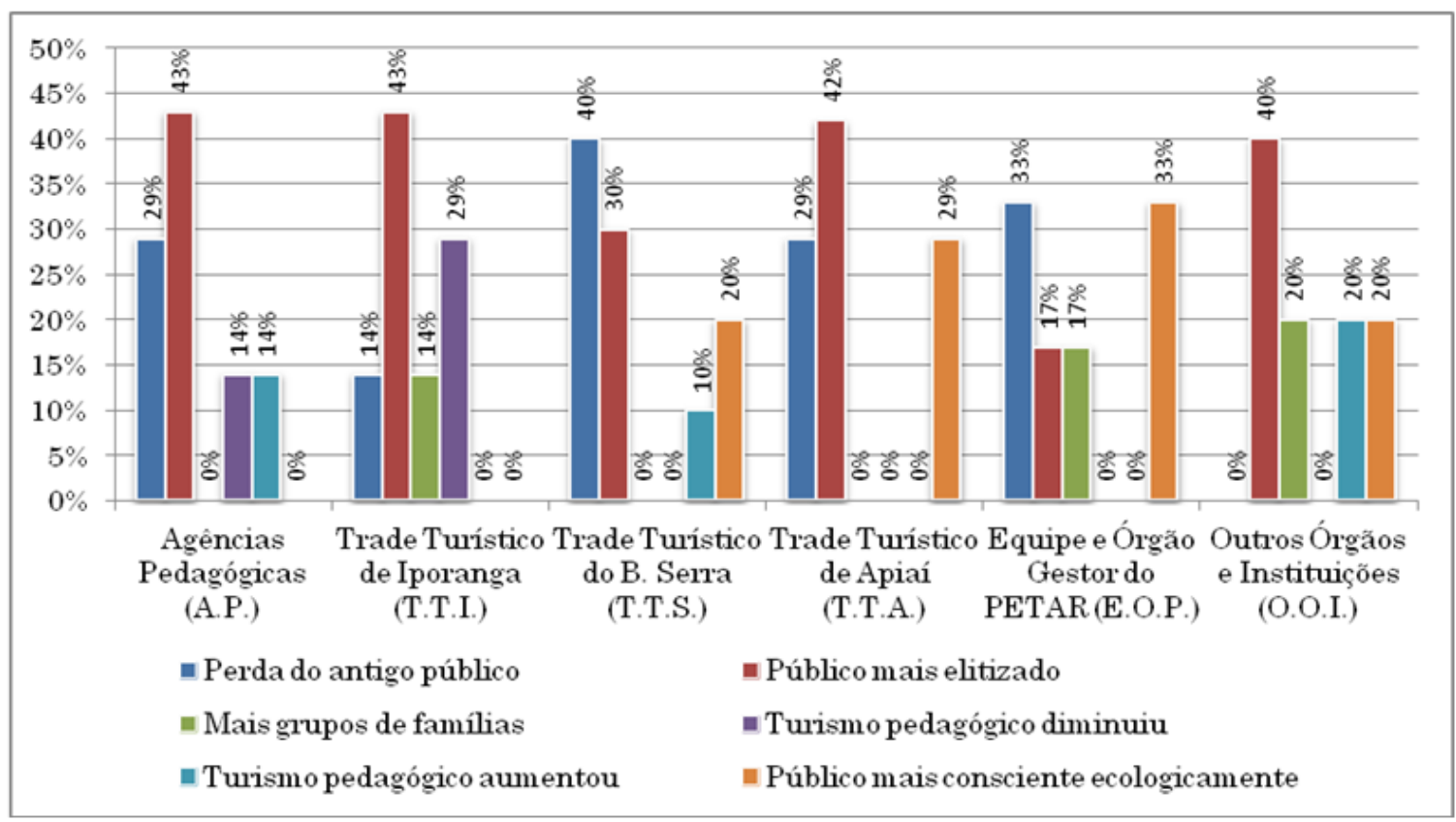

Figura 4: Mudanças no perfil dos visitantes pós-2008.

Figure 4: Changes in visitor's profile after 2008. 
Conforme ilustrado na Figura 4, quase todos os grupos de stakeholders exceto o grupo $\mathrm{OOI}$-, mencionaram a perda do antigo público que frequentava - Parque (destaque para $40 \%$ dos entrevistados do grupo TTS, onde estes visitantes mais se hospedavam - no Bairro da Serra). Esta mudança foi atribuída a fatores como a diminuição na quantidade de cavernas abertas à visitação, a impossibilidade de fazer roteiros alternativos nas cavernas abertas e, principalmente, pela obrigatoriedade de visitas guiadas nos roteiros turísticos.

De fato, o público que frequentava o PETAR desde os anos de 1970 era formado por uma parcela significativa de espeleólogos. Estes possuíam maior liberdade de atuação e não compreendiam o PETAR como destino turístico formatado (SCALEANTE, 2003; FIGUEIREDO, 2010; LOBO, 2017). Havia um inerente caráter de maior aventura, não somente enquanto segmento de turismo, mas amplamente ligado à possibilidade de desvendar o desconhecido (SPINK, 2012). Com a formatação dos roteiros condicionada pelo TAC pós2008, incluindo o acompanhamento obrigatório de monitor ambiental local, horários, tempo e tamanho de grupos de visitação definidos, a visitação perdeu essa essência anterior para estes visitantes tradicionais e houve aumento de preços. Nas palavras de um dos entrevistados, esta mudança fica evidente, não somente pelos que deixaram de vir, mas pelo novo grupo que começou a frequentar o Parque:

"Deixou de vir os aventureiros, que estão começando a voltar a vir pra cá, por causa de saudade ou vem pra trazer o filho ou o neto" (TTS 3).

A presença de grupos familiares foi mencionada por três grupos (TTI, EOP e OOI). Esta característica está entre os fatores que vem influenciando os empreendimentos turísticos locais ligados ao turismo, como pousadas. Até o início dos anos 2000, havia o predomínio de acomodações coletivas para abrigar grupos escolares, de amigos e espeleólogos, que eram os principais perfis de frequentadores do Parque. Todavia, muitas pousadas reconfiguraram suas acomodações para atender famílias (FOGAÇA, 2008; VEIGA, 2009).

Outras mudanças também foram observadas relacionadas à elitização do público-alvo, mencionada por todos os grupos de stakehoders, com destaque maior para os grupos AP (43\%), TTI (43\%), TTA (42\%) e OOI (40\%). Evidências foram observadas em campo, como: aumento do nível de conforto nas acomodações - inclusão de wi-fi para acesso à internet e condicionadores de ar - e surgimento de meios de hospedagem sofisticados, como um glamping - uma proposta derivada da prática de acampar, adaptada para uma acomodação sofisticada e despojada, com alto grau de exclusividade e pelo padrão de serviços prestados (BROCHADO; PEREIRA, 2017).

No entanto, tais mudanças de perfil de visitantes são recorrentes em destinos turísticos e atribuídas em pesquisas anteriores (e.g. PAVOVLICH, 2003; BUTLER, 2006) ao ritmo usual de alteração do turismo, sobretudo em áreas naturais. Butler (2006) descreve que o turismo se inicia com visitantes que nem se consideram turistas, que buscam uma viagem menos enquadrada nos moldes 
de um pacote turístico. Estes vão sendo substituídos - ou culminam por alterar suas preferências - por turistas que buscam roteiros prontos, pré-definidos e com maior conforto.

Outro aspecto acerca do perfil dos visitantes, mas que apresentou a maior discrepância entre as respostas, é sobre o turismo pedagógico. No PETAR, este tipo de turismo é o maior responsável pelo fluxo turístico fora dos feriados e férias escolares (FUNDAÇÃO FLORESTAL; EKOS BRASIL, 2010). Trata-se do turismo desenvolvido por escolas e universidades, para realização de atividades de estudo do meio, aulas de campo ou Educação Ambiental (NEIMAN; RABINOVICI, 2008). Enquanto alguns entrevistados - AP (14\%) e TTI (29\%) mencionaram a redução deste público, outros - AP (14\%), TTS (10\%) e OOI $(20 \%)$ - pontuaram o seu aumento. Algumas opiniões ilustram tais divergências:

\begin{abstract}
"Desde 2008, as nossas saídas pro PETAR aumentaram. Temos cerca de vinte saídas por ano pra lá, mas não tenho tanta certeza do porquê aumentou" (AP 1).

"O turismo pedagógico é o que mantém o nosso negócio, a nossa cadeia produtiva aqui. (...) Tivemos um aumento no público pedagógico" (TTS 2).
\end{abstract}

Sem explicações definitivas para as diferenças de opiniões, levanta-se a hipótese de uma alteração na dinâmica deste tipo de turismo, talvez com algumas agências perdendo público para outras e mesmo com a preferência em utilizarem mais os serviços do trade do bairro da Serra, que apontou seu aumento, em detrimento do trade de Iporanga, que apontou sua diminuição.

Ademais, quatro grupos mencionaram o "aumento da consciência ecológica" - nas palavras dos entrevistados - dos turistas pós-2008. Analisando as opiniões manifestadas, nota-se que esta menção se refere a um novo posicionamento de sensibilidade quanto ao ambiente, como definido por Cortês e Moretti (2013). Um exemplo é dado por um trecho de uma das entrevistas:

"O turista hoje sabe que não se deve descartar o lixo em qualquer lugar, a gente não precisa falar. Ele sabe que não pode depredar a mata. O que não sabe a gente fala, é o nosso serviço" (TTS 2).

A menção ao lixo é emblemática, pois o problema de descarte irregular de lixo nos atrativos do PETAR já havia sido pontuado por Sarfati e Sano (2012). Todavia, este aspecto de mudança pró-ambiente não deve ser atribuído diretamente ao embargo (2008), pois está relacionado às mudanças mais amplas na sociedade (COELHO et al., 2006; NEIMAN; RABINOVICI, 2008; CORTÊS; MORETTI, 2013). Alguns entrevistados percebem isso, tal como mencionado:

"Nesses nove anos, a questão ecológica, a questão da conscientização das pessoas tá mudando muito... então, dia-adia, você tem um visitante com mais cuidado, mais preocupação com a questão ambiental" (EOP 1). 
Este aspecto exemplifica que nem todas as mudanças devem ser atribuídas ao embargo de 2008. A própria elitização pode tanto estar ligada ao aumento das regras e custos de visitação quanto também à maturação do destino, como já pontuado por Lobo e Fogaça (2011).

\section{Impactos sobre o uso público}

A síntese das opiniões sobre a gestão do uso público no PETAR pós2008 é apresentada na Figura 5. Das alterações relatadas, foram atribuídos valores positivos aos construtos "mais segurança para os visitantes", "mais conservação ambiental" e "mais organização do turismo". Os três aspectos possuem forte relação entre si, sendo possível melhor compreendê-los ao analisar o contexto anterior a 2008 e as modificações realizadas.

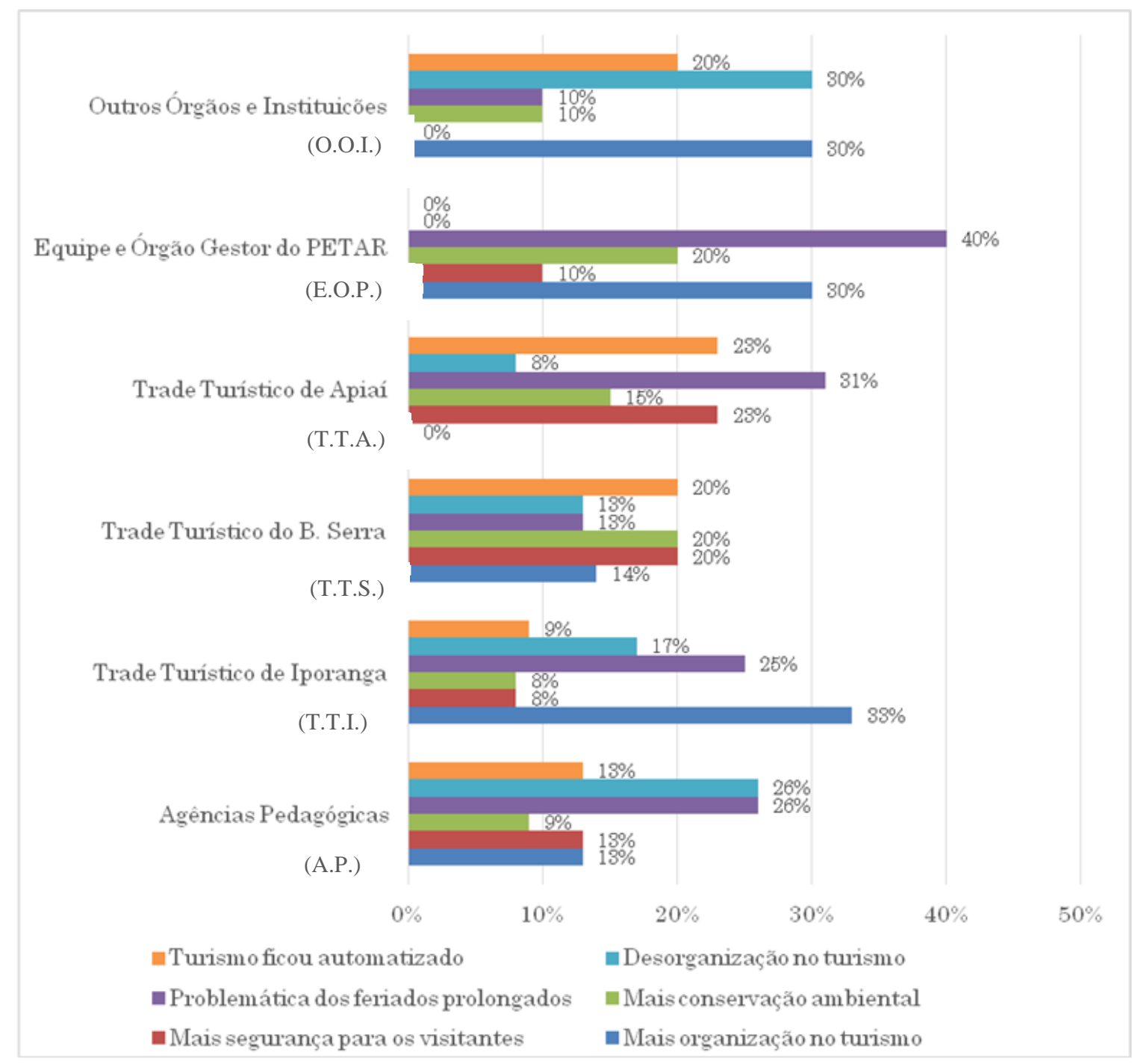

Figura 5: Impactos causados pelo embargo temporário das cavernas no uso público.

Figure 5: Impacts caused by the temporary closure of caves on tourist use.

O uso público do PETAR, entre 2000-2008, segundo Giatti e Rocha (2001) e Lobo (2017), era estruturado pelas seguintes condições: visitação em cerca de 30 cavernas (dentro e entorno do Parque); precária fiscalização dos roteiros; pouca ordenação turística quanto ao tempo de roteiro e tamanho dos 
grupos; concentração massiva da visitação em feriados, com tumulto em algumas cavernas; lixo nos atrativos; retirada acidental ou intencional de espeleotemas; e poluição do rio Betari por esgotos domésticos. Considerando os trabalhos de Rocha (2017) e Xavier et al. (2017), ficam evidentes algumas similaridades entre este parque e outras UCs que desenvolvem 0 espeleoturismo, principalmente em relação à vulnerabilidade a que estes ambientes estão submetidos quando se encontram em uma dinâmica de turismo não planejado.

Com o TAC, somente 12 cavernas foram reabertas ao turismo, com delimitação de roteiros, tamanho e tempo de permanência dos grupos, bem como a ratificação da obrigatoriedade do acompanhamento de monitores ambientais nos roteiros. Esta última regra merece destaque, sendo um dos principais pontos que contribuem para o aumento da segurança dos visitantes e do ambiente, como exemplificado a seguir:

"O risco de acidente antigamente era muito maior. Antes do fechamento tivemos mortes, né, e agora nenhuma. Se você pegar todas as ocorrências que tiveram, no máximo umas torções de pé" (TTS 4).

"Pras cavernas [a obrigatoriedade de monitor] foi muito mais positivo... Lugares mais conservados... Hoje a gente não registra depredação nas cavernas. Antes as pessoas levavam estalactites de lembrancinha, hoje isso não acontece por conta do guia. É muito raro encontrar lixo nas cavernas" (EOP 3).

Sobre haver mais organização/ordenamento no turismo pós-2008, a maior parte das menções foi feita, respectivamente, pelos grupos TTI (33\%), EOP $(30 \%)$ e OOI (30\%), mas sendo mencionado por todos os grupos. As regras que vieram com a reabertura das cavernas também são ligadas à mencionada "maior organização do turismo", pois o roteiro passou a ter hora para começar e terminar e a quantidade de pessoas por grupo diminuiu.

Os demais apontamentos referem-se aos impactos considerados negativos para o uso público do PETAR pós-2008, representados pelos construtos "desorganização no turismo", a "problemática dos feriados prolongados" e a "automatização do turismo". Nota-se que os apontamentos feitos pelos entrevistados divergem, pois uma parcela mencionou uma maior organização no turismo e outra parcela mencionou uma maior desorganização no turismo. Apenas o grupo representado pela Equipe e Órgão Gestor do PETAR não mencionou ter percebido uma maior desorganização. Todavia, $40 \%$ deste grupo mencionou ter notado a problemática acerca dos feriados prolongados, se relacionando à desorganização no turismo. Desde a reabertura das cavernas, os feriados prolongados registraram inúmeros problemas, como: horas de espera para entrar nas cavernas; filas de carros na entrada do Núcleo Santana; e a incerteza de quais cavernas serão visitadas no dia pela falta de um sistema de agendamento das visitas (LOBO, 2017; MASUTTI et al, 2017). As determinações provisórias do TAC - muitas delas em vigor até o fechamento deste artigo, em novembro de 2021 - modificaram a dinâmica da visitação com regras que não funcionam quando esbarram em um grande contingente de 
pessoas, faltando vagas para todos e influenciando negativamente a experiência do visitante. Esse quadro atribui-se, sobretudo, aos fatores: o estabelecimento de uma capacidade de carga abaixo da demanda real (LOBO, 2017) e a ausência de um sistema de agendamento das visitas (FOGAÇA; LOBO, 2011; NAKASHIMA, 2018). Segue um dos depoimentos obtidos durante um feriado prolongado:

"O parque acabou de me passar um rádio dizendo que a caverna Santana já esgotou a capacidade de carga dela do dia e ainda são onze horas da manhã!" (TTS 2).

A percepção de que o turismo ficou mais organizado ou desorganizado pode variar. Em dias de baixo fluxo turístico há mais organização, pois as regras estabelecidas pelo TAC funcionam bem nestas condições. Por outro lado, a desorganização acontece em dias de grande fluxo, como nos feriados prolongados.

Uma parte dos visitantes entrevistados acreditam que uma das soluções para os problemas dos feriados prolongados seria abrir mais cavernas, repetindo o que foi dito por visitantes entrevistados por Borsanelli e Lobo (2013). Porém, a análise dos dados de visitação evidencia que das 12 cavernas abertas, apenas 5 (Santana, Morro Preto, Água Suja, Ouro Grosso e Couto) tem um fluxo regular e, mesmo em feriados, as demais cavernas são pouco visitadas:

"A única caverna que tem limite de capacidade de carga muito próxima da saturação é a Santana. As outras estão bem abaixo" (EOP 3).

Quanto ao outro impacto negativo pontuado, cinco grupos mencionaram que o turismo ficou automatizado, fazendo referência a uma visitação com ressalvas de acesso a espaços antes visitados e à diminuição na quantidade de atrativos. Existe também a opinião de que a atratividade diminuiu, a qual seria ótima apenas para aqueles que conheceram o Parque depois da reabertura, como segue:

"Pro Parque foi melhor, mas quando estou como turista, acho que perdeu um pouco a emoção. Quem conheceu o antes, tá ruim agora" (OOI 3).

Os aspectos ilustrados refletem a mudança na cultura de visitação, retomando de forma nostálgica e indireta a fase de predomínio dos espeleólogos até o início dos anos 2000 (FIGUEREDO, 2010; LOBO, 2017) e o relativo ideário de aventura (SPINK, 2012). Mesmo com as novas regras e limites de visitação, o destino ainda é considerado uma atividade de aventura pela maioria dos visitantes (MASUTTI et al., 2017).

\section{Impactos causados às comunidades de entorno}

Em relação aos impactos causados às comunidades do entorno do PETAR, foram pontuados aspectos direta e indiretamente ligados ao turismo (Figura 6). Alguns foram analisados como negativos, devido às possíveis 
consequências indesejadas para as comunidades e para o Parque: prejuízos financeiros (nos primeiros meses/anos ou de um modo geral); surgimento de uma reserva de mercado; insegurança no trabalho do trade turístico; e outros problemas (êxodo, palmito etc.).

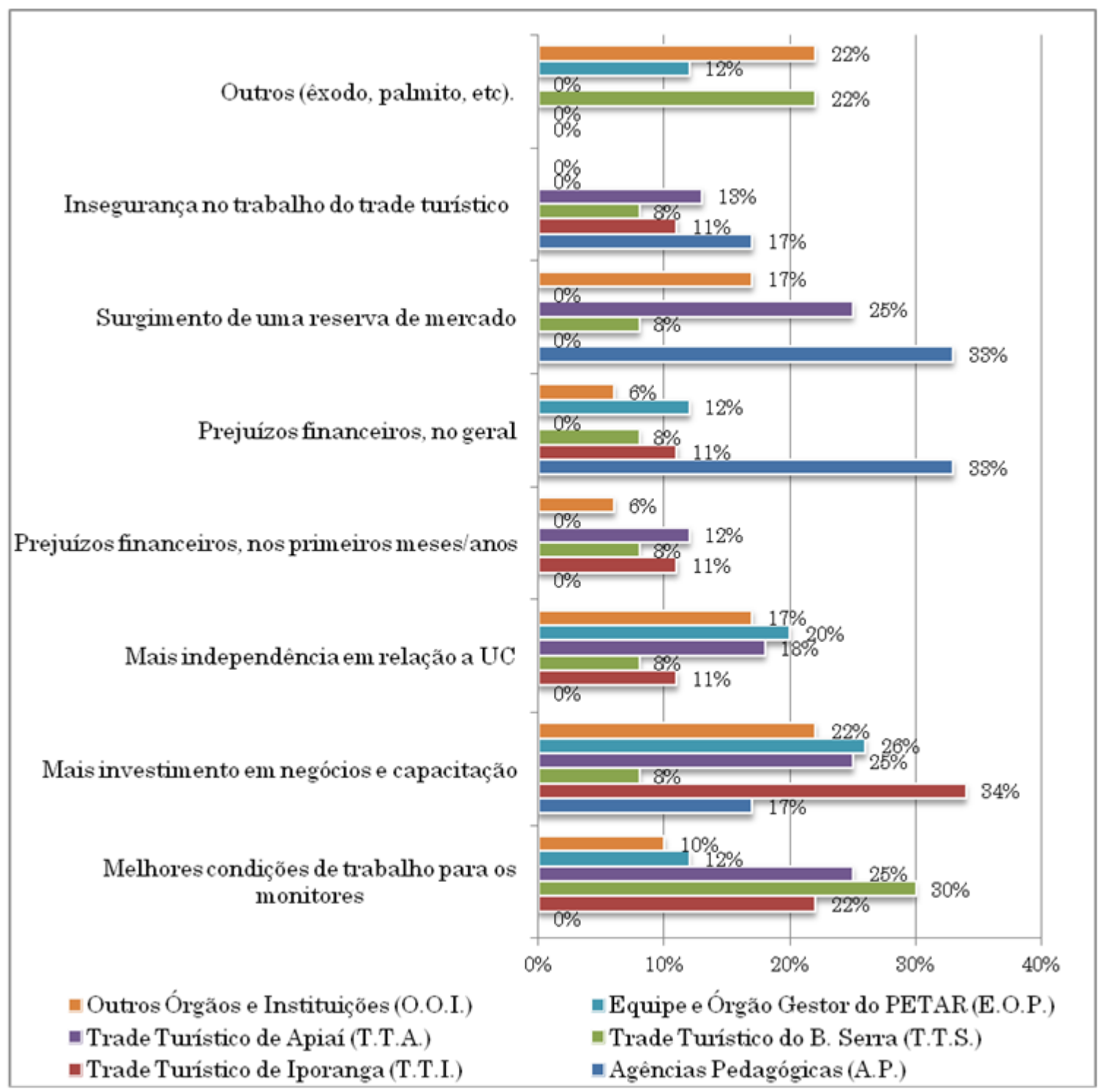

Figura 6: Impactos causados às populações de entorno.

Figure 6: Impacts caused to the surrounding populations.

Quanto aos prejuízos financeiros a curto prazo e de uma forma geral, estes foram pontuados por todos os grupos. A situação foi mais drástica durante o embargo e continuou desfavorável no restante de 2008, quando a visitação continuou abaixo da média regular de anos anteriores, tal como exemplificado por alguns dos stakehoders:

"Como a gente ia fazer? Aqui no bairro [Serra], em cada casa tem pelo menos um monitor, ou trabalha no Parque ou nas pousadas" (TTS 3). 


\begin{abstract}
"Apiaí socorreu o pessoal da Serra levando cestas básicas ... foi um movimento espontâneo dos monitores de Apiaí. Eles pediram pro comércio e pra gente doações. Eles [moradores do bairro da Serra] ficaram recebendo enquanto ficaram fechadas as cavernas" (OOI 2).

"O comércio de Apiaí ficou bem abalado, porque o pessoal da Serra compra muito em Apiaí... mercado, coisas pra pousada, lençóis etc. Daí que nós vimos a importância deles aqui pra economia" (OOI 4).
\end{abstract}

Entre as consequências da diminuição de visitantes, destaca-se o fechamento de pousadas na região. Veiga (2009) relata que entre 2006-2009 houve o fechamento de nove desses estabelecimentos. Durante a realização dos trabalhos de campo da presente pesquisa, constatou-se o fechamento de outras duas pousadas, atribuídas por seus proprietários à redução do fluxo de visitantes. Porém, é possível que a competitividade e investimentos desproporcionais - e não somente o embargo e suas consequências - tenham desfavorecido parte do empresariado local. Um dos entrevistados pontua sobre a diferença entre os possíveis afetados pela redução de visitantes:

"Os pequenos negócios sofreram mais do que as pousadas, que já estavam estruturadas, porque essas continuaram recebendo 0 fluxo menor e o excedente acabava não chegando nas menores" (TTS 3).

O segundo grupo de impactos negativos versa sobre o aparecimento de uma reserva de mercado, apenas não mencionada pelos grupos TTS e EOP. Aqueles que pontuaram sobre esta consequência comentaram que um grupo de empreendimentos e indivíduos teve benefícios na época do fechamento, dominando o turismo receptivo, tal como exemplificado:

"A gente prefere trabalhar sempre com os monitores autônomos, porque assim a gente ajuda a distribuir renda e a gente acaba fazendo uma pressão pras empresas de lá pagarem mais pros monitores deles. Isso dá muito mais trabalho pra gente, porque a gente tem que ligar um por um, pra cada monitor (...) Era muito mais fácil eu contratar só uma empresa e ela resolver isso com eles, mas assim a distribuição de renda é muito menor. Uma vez eu quis mesclar, pensei em contratar metade do serviço com uma agência de lá e a outra metade dos monitores, autônomo mesmo... mas não deu certo não, o cara disse "ou é tudo comigo ou não faço" (AP 1).

"Eu acho que o TAC é pior do que o fechamento. O TAC direcionou pra reserva de mercado, pra desvio de funções, uso clandestino de cavernas. Isso é culpa da comunidade também... lá ninguém reivindica nada... E por quê? Por quê está sendo bom pra eles. É uma reserva de mercado, que tem meia dúzia que comanda o sistema e não há interesse nenhum de mudar" (AP 3). 
"E o site que tem é feito pela pessoa que tem a maior parte dos ganhos lá... e ele ocupou um espaço que o estado deixou vago, porque você entra no site do estado, só tem informação irrelevante pro turista sobre o Parque ter trinta e cinco mil hectares de floresta ombrófila densa. O que que isso é relevante pro turista?" (AP 3).

Também foi constatada a sensação de insegurança no trabalho do trade turístico, a qual só não foi mencionada por aqueles que não trabalham comercialmente com os visitantes (EOP e OOI). Os demais grupos, compostos por pessoas que estão diretamente ligadas à operação do turismo, foram unânimes em relatar este problema. O foco da questão colocada pelos entrevistados é sobre a incerteza de quais e quantas cavernas poderiam ser visitadas por dia por um determinado turista. Com os limites de visitação impostos pelo TAC, adicionado à impossibilidade de se agendar previamente um roteiro, não há como garantir previamente ao visitante sobre o roteiro que ele conseguirá fazer, sobretudo em dias de maior movimento, tal como relatado:

"A gente não passa mais aquele roteiro fechado, dia 25 vai você visitar Santana, Morro Preto, Couto, cachoeira do Couto... e eu alerto que a gente só vai saber quais atrativos a gente vai visitar no dia" (TTS 1).

"A gente fala pra eles [administração das escolas]: "olha, no núcleo Santana a gente pretende fazer três, mas pode ser que sejam duas. Duas a gente garante, mas a gente não sabe quais vão ser essas duas. A gente dá prioridade pra Santana, porque tem bastante formação [de espeleotemas]. A segunda e a terceira vai depender da quantidade de pessoas que vai ter lá" (AP 1).

"Hoje na divulgação eu tenho que colocar sujeito à alterações climáticas e distribuição do fluxo turístico feito pela Fundação Florestal" (AP 3).

Outro problema derivado do TAC é a necessidade de os monitores ambientais chegarem mais cedo à portaria do Parque, pois com a impossibilidade de fazer reserva antecipada ${ }^{1}$, os grupos garantem a visitação por ordem de chegada. Então, em dias de maior movimento, formam-se filas de monitores ambientais antes mesmo da abertura do Parque, de forma a garantir que o grupo por eles representado consiga ir a uma determinada caverna. Somente após o término da visitação desta primeira caverna que o monitor consegue novamente registrar seu grupo para visitar outro roteiro no mesmo dia. Este sistema não ajuda nem o monitor nem o visitante. Para o visitante, além da insegurança de viajar e não saber se conseguirá ver determinado atrativo, existe também a pressa em terminar determinado roteiro para garantir a possibilidade de visitar outro. Com isso, perdem-se as janelas sensoriais da experimentação e do contato íntimo com o ambiente, interferindo na percepção e interpretação ambiental (NEIMAN; RABINOVICI, 2008; FENNELL, 2014). Para o monitor - ou mesmo as agências de receptivo -, ficam os inconvenientes de não poder oferecer garantias de visitação para seus clientes, além da necessidade de se 
deslocar com maior antecedência para o Parque, implicando em comprometimento de tempo e recursos.

Ademais, foram citados outros impactos negativos, como o êxodo rural e a extração ilegal do palmito juçara. Os resultados mostram que $87 \%$ dos entrevistados afirmaram conhecer pessoas que deixaram a região pela falta de emprego na época do embargo e logo depois:

"O que tem pra trabalhar aqui é o turismo, se você não consegue ser monitor ou trabalhar na pousada, você vai embora" (TTS 3).

Desta forma, entende-se que o embargo contribuiu para agravar 0 fenômeno do êxodo rural, em curso na região desde meados dos anos de 1930, conforme pontuado por Fogaça (2008).

Em contrapartida, o embargo temporário também foi visto como um gerador de impactos positivos para a comunidade, os quais foram sintetizados pelos construtos: "melhores condições de trabalho para os monitores"; "maior independência em relação à UC"; e "mais investimentos em negócios e capacitação".

A melhoria relativa na condição de trabalho dos monitores só não foi pontuada pelas agências pedagógicas. $O$ aspecto mais relevante da compreensão de uma condição melhor de trabalho foi o estabelecimento de um limite máximo de 8 visitantes sendo guiados por cada monitor. A definição de um horário limite de trabalho, dentro da lógica do horário comercial, também foi pontuada. Com estes fatores, o trabalho do monitor se tornou mais seguro e rentável, já que antes do TAC, era comum a existência de grupos de dezenas de visitantes com um único monitor, como relatado por um dos entrevistados:

"Antigamente, era muito difícil ganhar dinheiro. Uma excursão contratava um guia pra 40 pessoas, mas a diária era quarenta reais, pra guiar 40 pessoas. Hoje o guia cobra cento e cinquenta reais pra 8 [pessoas]" (TTS 1).

"Pro guia ficou muito mais seguro depois do fechamento, porque não tinha regra de oito pessoas por guia, limite de pessoas pra caverna. Hoje você tem que agendar horário pra entrar e tem horário pra sair" (TTS 4).

Outro impacto positivo foi a percepção de que era necessário se desvencilhar da dependência com o PETAR. Esta se refere tanto ao âmbito administrativo da rotina do turismo quanto aos atrativos para a visitação. Alguns trechos de relatos retratam esta menção:

"Nos vimos presos a uma gestão de uma unidade de conservação fechada. A gente viu que a gente precisava ir além no turismo e não ser tão dependente da unidade de conservação" (OOI 1). 
"O PETAR é muito importante, mas tem muita coisa interessantíssima fora do PETAR e é isso que nós vamos trabalhar" (OOI 5).

"Abrir novos atrativos no Parque não resolve... A solução é que tivessem outros atrativos fora do Parque... isso distribuiria a visitação na região e melhoraria o turismo no Parque nos feriados... Porque no Parque já cresceu quase tudo que tinha pra crescer relacionado à visitação. Temos dois moradores locais interessados em fazer esse estudo pra abrir caverna pra visitação... pra gestão do Parque seria muito bom..." (EOP 3).

"Precisa estruturar esses atrativos que estão fora do PETAR, pra ter mais alternativa pro turista e pra ele não vir só uma vez... e vai até aumentar pro monitor ambiental. Laje Branca (caverna), a região do Lajeado, caverna Cristal, tem o rio, abrir outras trilhas, a caverna Laboratório... no bairro Caximba tem caverna... e usar as águas daquele lugar né” (OOI 3).

A percepção de que é necessário haver independência em relação à UC e investir em novos atrativos também teve influência no fato das Prefeituras Municipais de Iporanga e de Apiaí buscarem novas alternativas no turismo e investir em melhorias na infraestrutura turística:

"Dos segmentos de turismo, Iporanga pode corresponder a quase todos. Nossa prioridade é desenvolver o turismo de base comunitária" (OOI 1).

"Fizemos um trabalho árduo com os hoteleiros de Apiaí, porque a gente passava vergonha com nossos hotéis... a gente começou a levar eles no Hotel SENAC, hotel escola. O nosso COMTUR ficou forte, fizemos muita capacitação e praticamente todos os hotéis foram reformados" (OOI 5).

Sobre a ampliação nos investimentos em negócios e capacitação, esta refere-se tanto a investimento em negócios já existentes - como reformas quanto em novos empreendimentos. Tal aspecto foi mencionado por todos os grupos de stakeholders. Além disso, os entrevistados aparentaram que, de um modo geral, as questões mais problemáticas relativas ao embargo já haviam sido superadas. Exemplos foram dados por falas relativas à retomada dos investimentos em empreendimentos turísticos na região e à possível melhoria na geração de renda para os envolvidos com o trade turístico:

"Muita coisa cresceu, camping, pousada surgiu..." (TTS 6).

"Esse ano [2017] acho que tem treze feriados prolongados, então é a época do guia que quiser comprar moto, fazer casa, fazer alguma coisa que ele sonha... é esse ano, esse é um ano brilhante!" (TTS 4). 
Assim, observa-se que com a retomada da visitação e o crescimento no número de visitantes, embora o Parque "não seja mais o mesmo" - sensação percebida na fala de diversos entrevistados -, a sensação geral com o turismo permanece positiva. Este aspecto é sobremodo relevante, considerando que o turismo praticado de modo responsável com o ambiente - nos moldes do Ecoturismo enquanto forma de visitação (FENNELL, 2014) e envolvendo as comunidades locais (BARTHOLO Jr et al., 2011) - é uma das poucas alternativas de desenvolvimento socioeconômico para a região (NAKASHIMA, 2018).

\section{Conclusões}

O fechamento das cavernas no início de 2008 deixou marcas indeléveis no turismo e nas comunidades locais do PETAR. Mesmo com a reabertura das cavernas ocorrendo pouco depois, a nova proposta de gestão impactou a operação do turismo na região. Não restaram dúvidas de que as medidas impostas pelo TAC resultaram na organização parcial do uso público, na ampliação da segurança para os visitantes e operadores de turismo e no aumento da efetividade da conservação ambiental. Embora este processo não tenha sido fruto de uma mudança de consciência dos envolvidos, mas sim, uma imposição legal, pode-se compreender o balanço final como positivo. Entre as evidências que dão suporte a esta interpretação, destacam-se a menção aos benefícios aos monitores pelo limite de pessoas atendidas por grupo, a definição de horário de trabalho e a percepção de que o turismo na região precisa se ampliar para além do Parque.

Por outro lado, também foram percebidos problemas para as comunidades locais, consequentes deste processo. Além dos impactos financeiros diretos e indiretos, destaca-se a reorganização do setor do turismo com algumas reservas de mercado e os problemas para os visitantes e monitores pela impossibilidade do agendamento na visitação dos atrativos - os quais estão apenas parcialmente resolvidos, ao menos até o fechamento deste artigo (set./2021). Neste sentido, a falta de celeridade da gestão do Estado no que diz respeito à implantação dos PMEs - nos quais estão previstas medidas como o aumento da capacidade de carga dos roteiros e um sistema de reservas para os roteiros - amplia estes problemas.

Além disso, ressalta-se a mudança de perfil de público. Esta, no entanto, não é atribuída ao embargo, mas à alteração no modelo de gestão do turismo no PETAR. Com a adoção de um sistema de visitação com maior controle e aparente segurança ao visitante, outro público foi atraído, à medida que o anterior, que era mais desprendido de regras de controle mais rígidas, foi se afastando. Entende-se esta mudança como um fenômeno normal nos ciclos dos destinos turísticos. No entanto, o diferencial observado no PETAR em relação ao relatado em pesquisas anteriores é o fato desta transição ter ocorrido de forma abrupta, condicionada por um fator externo que alterou significativamente a lógica existente. Este aspecto foi compreendido como o mais emblemático do caso estudado.

Como fruto do processo estudado, espera-se que situações análogas de planejamento e gestão do turismo possam ser administradas sem que eventos traumáticos evitáveis ocorram. Desta forma, as relações sociais entre os grupos 
envolvidos - locais e visitantes - e destes com o ambiente poderão ter seu curso definido em função de questões intrínsecas à realidade local, ao invés de serem conduzidas como respostas apressadas para situações adversas e arbitrárias.

\section{Referências}

ALVES, H.P.F. Análise dos fatores associados às mudanças na cobertura da terra no Vale do Ribeira através da integração de dados censitários e de sensoriamento remoto. 2004. 337f. Tese (Doutorado em Ciências Sociais) Universidade Estadual de Campinas, Campinas, 2004.

BARTHOLO Jr., R.S.; CAMPOS, A.; BURSZTYN, I.; EGREJAS, M.; LIMA, R.P. Marco referencial teórico para o turismo de base comunitária. Rio de Janeiro: UFRJ, 2011. 28 p.

BORSANELLI, F.A.; LOBO, H.A.S. Percepções dos visitantes sobre a evolução do espeleoturismo no PETAR face ao fechamento das cavernas turísticas em 2008. Anais do 32ํㅡㄹ Congresso Brasileiro de Espeleologia, 2013. Barreiras. Campinas: SBE, 2013. p.45-54.

BROCHADO, A.; PEREIRA, C. Comfortable experiences in nature accommodation: Perceived service quality in Glamping. Journal of Outdoor Recreation and Tourism, v.17, p.77-83, 2017.

BUTLER, R.W. The concept of a tourist area cycle of evolution: implications of management of resources. In: BUTLER, R.W. The tourism area lyfe cycle: applications and modifications. Clevedon: Channel View Publications, 2006. p.312.

BYRD, E.T. Stakeholders in sustainable tourism development and their roles: applying stakeholder theory to sustainable tourism development. Tourism Review, v. 62, n.2, p.6-13, 2007.

COELHO, J.A.P.M.; GOUVEIA, V.V.; MILFONT, T.L. Valores humanos como explicadores de atitudes ambientais e intenção de comportamento próambiental. Psicologia em Estudo, v.2, n.1, p.199-207, 2006.

CÔRTES, P.L.; MORETTI, S.L.A. Consumo Verde: Um Estudo Transcultural Sobre Crenças, Preocupações e Atitudes Ambientais. Revista Brasileira de Marketing, v.12, n.3, p.45-76, 2013.

FENNELL, D. A. Ecotourism. London: Routledge, 2014. 288 p.

FIGUEIREDO, L.A.V. Cavernas como paisagens racionais e simbólicas: imaginário coletivo, narrativas visuais e representações da paisagem e das práticas espeleológicas. 2010. Tese (Doutorado em Geografia), Universidade de São Paulo, 2010.

FOGAÇA, I.F. Estudo das transformações da estrutura física do bairro da Serra, entorno do PETAR, em decorrência da atividade turística. Turismo e Paisagens Cársticas, v.1, n.1, p.29-42, 2008.

FUNDAÇÃO FLORESTAL (SP); INSTITUTO EKOS BRASIL (Coords.) Plano de manejo espeleológico do Parque Estadual Turístico do Alto Ribeira. São Paulo: Fundação Florestal, 2010. 765 p. 
GIATTI, L.L.; ROCHA, A.A. Impactos ambientais do turismo na região do PETAR - Parque Estadual Turístico do Alto Ribeira - São Paulo - Brasil. Anais do 13TH International Congress of Speleology, 2001. Brasília. Campinas: SBE, 2001.

HOGAN, D.J.; CARMO, R.L.; ALVES, H.P.F.; RODRIGUEZ, I.A.; Sustentabilidade no Vale do Ribeira. Ambiente \& Sociedade, v. 2, n 3/4, p.151175, 1999.

IMRAN, S.; ALAM, K.; BEAUMONT, N. Environmental orientations and environmental behaviour: Perceptions of protected area tourism stakeholders. Tourism Management, v.40, p.290-299, 2014.

KARMANN, I.; FERRARI, J.A. Carste e Cavernas do Parque Estadual Turístico do Alto Ribeira (PETAR), SP: sistemas de cavernas com paisagens subterrâneas únicas. In: DNPM. Sítios Geológicos e Paleontológicos do Brasil. Brasília: DNPM, 2002. p.401-413.

LOBO, H.A.S. Capacidade de carga real (CCR) da caverna de Santana, Parque Estadual Turístico do Alto Ribeira (PETAR) - SP, e indicações para o seu manejo turístico. Geociências, v.27, n.3, p.369-385, 2008.

LOBO, H.A.S. Entre 117 e 1344: qual o limite diário recomendável para a visitação da caverna Santana (PETAR-SP)? Revista Brasileira de Ecoturismo, São Paulo, v.10, n.3, p.645-669, 2017.

LOBO, H.A.S.; FOGAÇA, I.F. Planejamento Turístico em Unidades de Conservação Públicas: Espeleoturismo no Parque Estadual Turístico do Alto Ribeira (PETAR), SP. Anais do VII Seminário da Associação Nacional de Pesquisa e Pós-Graduação em Turismo. Univali: Camboriú, 2011. p.1-12.

MARINHO, M.A. (Coord.). Plano de uso recreativo do PETAR, Iporanga e Apiaí/SP. São Paulo: WWF/lng Ong, 2002.

NAKASHIMA, M.R. O PETAR: geografia, contradições e desenvolvimento. Tese (Doutorado) - Faculdade de Filosofia, Letras e Ciências Humanas da Universidade de São Paulo. 2018.

NEIMAN, Z.; RABINOVICI, A. Espeleoturismo e Educação Ambiental no PETAR - SP. Turismo e Paisagens Cársticas, v.1, n.1, p.57-65, 2008.

MASUTTI, R.F.; LOBO, H A.S.; SANTOS, G.E.O.; TRAVASSOS, L.E.P.; ALVES, J.V.I.; PIRES, A.P.; GIUSTI, M.M. Percepção de lotação e nível de satisfação dos visitantes como contribuições para a capacidade de carga turística das avernas do PETAR (Iporanga, SP): resultados preliminares. In: Anais do $34^{\circ}$ Congresso Brasileiro de Espeleologia. Ouro Preto. Campinas: SBE, 2017. p.643647.

MORAES, R. Análise de conteúdo. Revista Educação, Porto Alegre, v.22, n.37, p.7-32, 1999.

OLABUENAGA, J.I.R.; ISPIZUA, M.A. La descodificación de la vida cotidiana: metodos de investigacion cualitativa. Bilbao: Universidad de Deusto, 1989.

PAVOVLICH, K. The evolution and transformation of a tourism destination network: the Waitomo Caves, New Zealand. Tourism Management, v.24, n.2, p.203-216, 2003. 
RABINOVICI, A. ; NEIMAN, Z. Embargo às cavernas em São Paulo. O Eco, Rio de Janeiro, 28 fev. 2008. Disponível em < https://oeco.org.br/analises/16816oeco-26326/>. Acesso: 17 nov.2021.

ROCHA, P.R.R. Avaliação dos impactos ambientais causados pelo espeleoturismo na caverna de Terra Ronca do Parque Estadual Terra Ronca GO. Monografia (Graduação) - Faculdade UnB Planaltina, Universidade de Brasília. 2017.

ROSA, P.F.; CARVALHINHO, L.A.D.; SOARES, J.A.P. A participação de stakeholders no planejamento e gestão do turismo e da recreação em áreas protegidas: Fundamentos para 0 processo participativo. Tourism \& Management Studies, v.12, n.2, p.96-106, 2016.

SARFATI, G.; SANO, N.N. Estudo Comparado da Gestão das Visitações nos Parques Estaduais Turísticos do Alto da Ribeira (PETAR) e Intervales (PEI). Turismo em Análise, v.23, n.1, p.207-237, 2012.

SAUTTER, E.; LEISEN, B. Managing stakeholders a Tourism Planning Model. Tourism Management, v.26, n.2, p.312-328, 1999.

SAVAGE, G.T.; NIX, T.W.; WHITEHEAD, C.J.; BLAIR, J.D. Strategies for assessing and managing organizational stakeholders. Academy of Management, v.5, n.2, p. 61-75, 1991.

SCALEANTE, J.A.B. O impacto da visitação intensiva em cavernas. Anais do 27ํㅡㄹ Congresso Brasileiro de Espeleologia. Januária: SBE, 2003. p. 72-83.

SPINK, M.J.P. Aventura, liberdade, desafios, emoção: os tons do apelo ao consumo do risco-aventura. Revista de Ciências Sociais, n.37, p. 45-65, 2012.

UNESCO. Atlantic forest south-east reserves. Paris: Unesco, 1999. Disponível em: <http://whc.unesco.org/en/list/893>. Acesso em: 15 Fev. 2018.

VEIGA, A.C.P. Perspectivas socioeconômicas da população do bairro da Serra em relação à elaboração do Plano de Manejo Espeleológico do PETAR - Parque Estadual Turístico do Alto Ribeira. Monografia (Bacharelado em Turismo) Universidade Estadual Paulista "Júlio de Mesquita Filho", Rosana, 2009.

XAVIER, F.V.; RIBAS, R.D.; BRAZ, A.M. Avaliação de impactos socioambientais na Gruta da Lapinha, Lagoa Santa/MG e seu entorno pela atividade turística. Geografia (Londrina). v.26. n.1. p.19-33, 2017.

\section{Nota:}

${ }^{1}$ Este aspecto foi pontuado na pesquisa e preservado, para efeito de manter a fidelidade dos dados obtidos e registro histórico da menção ao problema. No entanto, em out./2020 foi implantado um sistema online de compra e reserva de ingressos, por caverna. No início de 2021, no entanto, o contrato com a empresa que prestava o serviço foi rescindido, por não atender ao esperado pela Fundação Florestal, órgão responsável pela gestão das UCs paulistas. Desde então e até o fechamento deste artigo (dez/2021), um agendamento provisório está sendo feito diretamente com os Parques ou em suas portarias, mediante disponibilidade, até que a situação possa ser resolvida. 
Francesca Antoniella Borsanelli: Universidade Federal de São Carlos, Sorocaba, SP, Brasil.

E-mail: francescaborsanelli_@hotmail.com

Link para curriculum lattes: http://lattes.cnpq.br/2472990663651152

Zysman Neiman: Universidade Federal de São Paulo, Diadema, SP, Brasil. Email: zneiman@gmail.com

Link para o currículo Lattes: http://lattes.cnpq.br/6435341856481082

Heros Augusto Santos Lobo: Universidade Federal de São Carlos, Sorocaba, SP, Brasil.

E-mail: heroslobo@ufscar.br

Link para curriculum lattes: http://lattes.cnpq.br/9405961078398915 